\title{
The influence of ovulation on postural stability (Biodex Balance System) in young female
}

\author{
Eun-Sook Sung', Jung-Hyun Kim ${ }^{2 * *}$ \\ 'Department of Sports Rehabilitation, College of Health Welfare, Woosong University, Daejeon, Korea \\ 2Department of Physical Therapy, College of Health Welfare, Woosong University, Daejeon, Korea
}

The purpose of this study was to examine the influence of ovulation (OV) on dynamic balance in young female. Thirty-two eumenorrheic healthy women participated in Biodex Balance System (BBS) test for postural stability and a limit of stability menstrual cycle. BBS was tested in the menses (MS), OV, and luteal phase (LP). The limits of stabilities (total, forward-left, forward-right, backward-left, and backward-right) were significantly higher in the OV (total, $61.44 \pm 14.77$; forward-left, $67.50 \pm$ 15.17; forward-right, $69.50 \pm 14.43$; backward-left, $64.00 \pm 20.32$; and backward-right, $69.06 \pm 13.59$ ) than in the MS (total, $55.44 \pm 14.63$; forward-left, $60.00 \pm 15.98$; forward-right, $62.17 \pm 9.78$; backward-left, $57.83 \pm 19.09$; and backward-right, $57.28 \pm 13.73)$. Furthermore, the $\operatorname{LP}(65.11 \pm 13.79)$ was a significantly higher limit of stability than MS $(57.28 \pm 13.73)$ during backward-right. The present study showed that estrogen negatively influences postural stability. The postural sway in limits of stabilities (total, forward-left, forward-right, backward-left, and backward-right) were significantly the greatest in the OV. Since there is a different postural stability between MS, OV, and LP, this should be taken into account when devising training programs to avoid risk factor of fall and joint injury.

Keywords: Menstrual cycle, Ovulation, Postural balance

\section{INTRODUCTION}

The purpose of the postural control system is to support balance orientation and stability. Define of postural orientation is to maintain the appropriate interaction between body segment, task and environment (Horak, 2006) and postural stability can be defined as the ability of an individual to maintain the center of mass, or more specifically, it is stability limits. Limits of stabilities (LOS) are the greatest distance in direction and the body can lean away from a midline vertical position without falling (Adkin et al., 2005; Bartolić et al., 2005; Mancini et al., 2008; Schieppati et al., 1994). Estrogen could significant influence postural stability as well as muscular coordination because estrogen can affect directly and indirectly the female neuromuscular system (Rozzi et al., 1999). Other study reported that muscle relaxation is significant increased during the ovulatory phase of the menstrual cycle (Sarwar et al., 1996). Yu et al. (1999) have reported that there are estrogen receptors in the human anterior cruciate ligament (ACL) and these estrogen receptors may have relationship with ACL and an effect on the ligament laxity. Estradiol concentration peaks induce the ligament laxity of ACL during menstrual cycle (Lee et al., 2014). Previous studies have shown that there is more laxity at the ankle at ovulation (OV) versus other periods of the menstrual cycle (Shultz et al., 2012). Estrogens and androgens have been reported to influence verbal fluency, performance on spatial tasks, verbal memory tests, and fine motor skills (Hampson, 1990; Kimura, 1992; Sherwin, 1994). During the menstrual cycle, as the levels of estrogen and progesterone in the body undergo dynamic regulation, the effects of these hormones on the central nervous system (CNS) will also change (Woolley, 1999). Apart from their well-known estrogen and progesterone are steroid hormones that have many actions in the CNS (Fridén et al., 2003a). Estrogen and progesterone induce regulation of synapse formation and excitability may play a role in catamenial epilepsy, which varies in frequency during the menstrual cycle (Bonuccelli et al., 1989). Consequences of estrogen loss in females may include loss

\footnotetext{
${ }^{*}$ Corresponding author: Jung-Hyun Kim (iD https://orcid.org/0000-0002-4710-8145 Department of Physical Therapy, College of Health Welfare, Woosong University, 171 Dongdaejeon-ro, Dong-gu, Daejeon 34606, Korea

Tel: +82-42-630-4625, Fax: +82-42-630-4611,

E-mail: junghyunkim9144@gmail.com

Received: May 16, 2018 / Accepted: July 14, 2018
}

This is an Open Access article distributed under the terms of the Creative Commons Attribution Non-Commercial License (http://creativecommons.org/licenses/by-nc/4.0/) which permits unrestricted non-commercial use, distribution, and reproduction in any medium, provided the original work is properly cited. 
of synaptic connections in hippocampus (Woolley and McEwen, 1992) or decline in basal forebrain cholinergic function in the absence of circulating estrogens (Luine, 1985).

The fluctuation of estrogen and progesterone influences qualitatively or quantitatively on muscle strength, muscle type 2 fiber hypertrophy and nuclei-to-fiber ratio between menses (MS), OV, and luteal phase (LP) (Sung et al., 2014). Moreover, circulating of hormone levels may differentially contribute of muscle strength in adult females (McEwen, 1994). Grunfeld and Gresty (1998) have demonstrated women participated in 9 months around the world yacht race experienced an increase in motion sickness during days 1-7 in the MS phase and a high postural instability in the early follicular phase of the menstrual cycle (Darlington et al., 2001). Another study has reported postural control in women through different phases of the menstrual cycle and reported a greater postural sway in the LP and early follicular phase as compared to the OV. In addition, Fridén et al. (2003b) showed a significant greater displacement area, as an indicator of impaired postural control, in the LP in women with premenstrual syndrome, and the effect of estrogen on these receptors both directly and indirectly affects the female neuromuscular system (Rozzi et al., 1999). On the other hand, Hertel et al. (2006) demonstrated that there is no difference in postural control during the menstrual cycle (Fridén et al., 2003b; Fridén et al., 2005). However, most previous studies have reported that sex hormones might have an impact on both ligament laxity and muscular coordination (Petrofsky and Lee, 2015). Whether this difference balance is due to a central nervous effect of estrogen and it is improved muscle strength (Sung et al., 2014), altered soft tissues, or a general improvement in the quality of life remains unknown. Therefore, the purpose of the present study was to investigate differences in anterior/posterior and medial/lateral posture activity and stability whether estrogen can be effected the postural stability during the menstrual cycle where estradiol concentration is lowest (MS), rapid highest (OV), and highest (LP) of the menstrual cycle. If there is a differences in postural stability, estradiol fluctuation may cause a ligament and muscular stability.

\section{MATERIALS AND METHODS}

\section{Participants}

Thirty-two female students were recruited, with a mean age of $19.83 \pm 0.92$ years, height of $160.67 \pm 6.53 \mathrm{~cm}$, weight of $58.50 \pm 6.67$ and body mass index $22.69 \pm 2.54 \mathrm{~kg} / \mathrm{m}^{2}$ (Table 1). The subjects were selected from the following inclusion criteria:
Table 1. General characteristics of participants $(n=32)$

\begin{tabular}{lr}
\hline Characteristic & \multicolumn{1}{c}{ Value } \\
\hline Age $(\mathrm{yr})$ & $19.83 \pm 0.92$ \\
Height $(\mathrm{cm})$ & $160.67 \pm 6.53$ \\
Weight $(\mathrm{kg})$ & $58.50 \pm 6.67$ \\
Body mass index $\left(\mathrm{kg} / \mathrm{m}^{2}\right)$ & $22.69 \pm 2.54$ \\
\hline
\end{tabular}

Values are presented as mean \pm standard deviation.

healthy physical condition women without any neurological or movement disorder, nonsmokers, regular menstruation, any other medication that might interfere in hormone levels and sedentary or recreationally active. Moreover, they had not been taking oral contraceptives or any other hormonal treatments for at least one year prior to study. Only subjects who reported, that they had a regular basal temperature fluctuation and regular menstrual cycle. All subjects were informed about the procedures and risks of the study and written informed consent prior to the study. Approval for the experimental protocol was obtained from the Ethics Committee of the Woosong University, Korea (approval number: 1041549-17024-SB-56-01).

\section{Basal body temperature and menstrual cycle determination}

Before starting testing, all subjects measured their basal body temperature for 6 menstrual cycles (approximately 24 weeks) to observe the regular menstrual cycle. The fluctuation of basal body temperature was used to identify the phases of the menstrual cycle and this result was used to predict the OV. The subjects measured their basal body temperature orally with a digital thermometer for one minute every morning throughout the entire study period at the same time before getting out of bed. Basal body temperature was suggested as an OV indicator and defined as the low point in the temperature curve seen at the base of the rise to the hyper-thermic phase and the occurrence of $\mathrm{OV}$ was defined when an increase in basal body temperature of at least $0.3^{\circ} \mathrm{C}$ was measured (Kelly, 2006; Owen, 1975). If subject have no significant increase in basal body temperature, i.e., no OV, was excluded from the whole study.

\section{Biodex Balance System}

Biodex Balance System (BBS) was measured separately two times in MS (5th day of first bleeding), OV (peak of basal temperature) and, LP (LP: 25th day of first bleeding) during two menstrual cycles (approximately 8 weeks) and the result was calculated the mean value. To measure postural stability, LOS and fall risk this study used a commercially available balance device, the BBS (Biodex Medical Systems, Shirley, NY, USA). Using of 


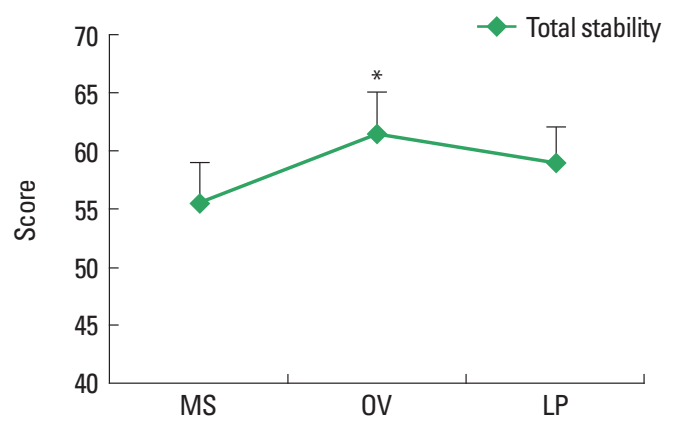

Fig. 1. The difference of total limit of stability in menses, ovulation and luteal phase. MS, memses; OV, ovulation; LP, luteal phase. *Significantly different compared to the MS $(P<0.05)$.

overall stability index is assessed for participants sway. The results of BBS calculated the anterior/posterior index, medial/lateral index, and overall stability index during a given task. These indices were calculated using the degree of oscillation of the platform, in which low values indicated that the individual had good stability.

For each mode, three tests were measured and we took to consider the subject index. Using of LOS for standing balance is defined as subject's vertical balance. Results of LOS can be assessed the integration of the sensory and motor control because posture balance plays an important role in daily activities.

During the fall risk test, the platform is flexible and subjects' sway is used to assess the fall risk index. Two sets of 20-sec test each at a stability level of 8 measured with 10 -sec rest between sets.

Fluctuations around the zero point are presented as the findings of this test (Ibrahim et al., 2016).

\section{Statistical analysis}

IBM SPSS Statistics ver. 22.0 (IBM Co., Armonk, NY, USA) was used for data processing and analysis in this study. Descriptive analysis was used for general characteristics. One-way repeated measure analysis of variance was used to decide the influence of each postural sway variable in MS, OV, and LP during menstrual cycle. Also Bonferroni post hoc test was applied and the statistical significance $P$-value was less than 0.05 .

\section{RESULTS}

This study revealed that limits of stabilities (LOS) (total, forward-left, forward-right, backward-left, and backward-right) were significantly higher in the OV (total, 61.44 \pm 14.77 ; forward-left, $67.50 \pm 15.17$; forward-right, $69.50 \pm 14.43$; backward-left,

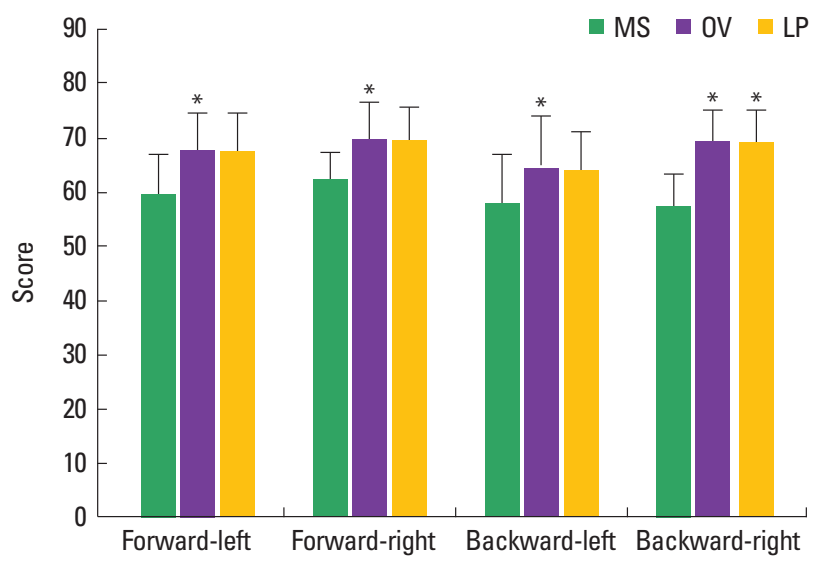

Fig. 2. The different effect of limits of stabilities in menses, ovulation and luteal phase. MS, memses; OV, ovulation; LP, luteal phase. *Significantly different compared to the $\mathrm{MS}(P<0.05)$.

$64.00 \pm 20.32$; and backward-right, $69.06 \pm 13.59$ ) than in the MS (total, $55.44 \pm 14.63$; forward-left, $60.00 \pm 15.98$; forward-right, 62.17 \pm 9.78 ; backward-left, $57.83 \pm 19.09$; and backward-right, $57.28 \pm 13.73)(P<0.05)$ (Fig. 1). Furthermore, the LP $(65.11 \pm$ 13.79) had a significantly higher LOS than MS $(57.28 \pm 13.73)(P<$ $0.05)$. However, we did not find significant difference between MS, $\mathrm{OV}$ and, LP on postural stability during menstrual cycle (Fig. 2).

\section{DISCUSSION}

In the present study, the investigators determined the influence of $\mathrm{OV}$ in the postural stability and LOS in young female. LOS is the greatest distance in direction and the body can lean away from a midline vertical position without falling (Adkin et al., 2005; Bartolić et al., 2005). LOS are determined not only biomechanical body, but also other factors, it is included as cognitive, postural control and, environment (Holbein and Redfern, 1997). Generally, normal menstrual cycle is divided into 2 phases (follicular phase and LP) (Girdler et al., 1993; Sato et al., 1995), 3 phases (follicular phase, OV, and LP) (Stoney et al., 1990), and 5 phases (early follicular phase, late follicular phase, OV, early LP, and late LP) (Laessle et al., 1990) and there is a hormone fluctuation across these stages in estrogen and progesterone.

In our study, we tested the BBS 3 times during two menstrual cycles: MS, OV, LP in the menstrual cycle. Specially, our study focused the fluctuation of estrogen concentration; serum levels of estrogen is low in the MS, only estrogen is elevated in the OV, and hormone concentration of estrogen and progesteron are elevated together in the LP. We observed a significantly greater each pos- 
tural sway variable of total stability, forward-left, forward-right, backward-left, and backward-right in the OV, when the estradiol concentration peaks, as compared to in the MS and LP.

Estrogen is the influence on the CNS including the higher motor centers, where it binds to membrane bound receptors and influences transmitter systems in the brain (Fridén et al., 2003b). In addition, hormone fluctuation of estrogen has effects on motor control and muscle strength (Sarwar et al., 1996; Sung et al., 2010) and, in further research; more emphasis should be placed on the investigation of neuromuscular factors that may be related to increased ACL injuries in female athletes (Posthuma et al., 1987). There are both alpha and beta receptors in tendons, ligaments and in skeletal muscle altering neuromuscular control and myofascial force transmission pathways during the menstrual cycle (Huijing and Jaspers, 2005; Lemoine et al., 2003). The effect of estrogen on these receptors both directly and in directly affects the female neuromuscular system (Rozzi et al., 1999). Previous studies have reported there is more laxity at the ankle in the OV phase versus other phases during menstrual cycle (Shultz et al., 2012). High laxity at the knee and foot can lead to poorer balance. We assume that if there were greater knee and ankle ligament elasticity at OV, balance would be impaired. Our study supports the previous studies, there are a greater reduction in balance ability in the $\mathrm{OV}$ than in the MS. Likewise, Fridén et al. (2003a) reported a significant increase in postural sway in the mid-LP, when estrogen levels are increased peak level and Shultz et al. (2012) also showed a greater ankle laxity in the OV than in other menstrual phases. Moreover, some studies have demonstrated that the changes in estrogen and progesterone levels during the menstrual cycle may have an effect on neurological function (Woolley, 1999). Zazulak et al. (2006) reported that estrogen is existed on human ligament and may affect the collagen structure and metabolism and estrogen. Moreover, estrogen fluctuation during menstrual cycle may a role in fibroblast proliferation and collagen formation in cell cultures and influence on decrease of soft tissue tension. Specifically, the results of our study can be supported that the greater postural sway is in the OV, i.e., when serum concentrations of estradiol peak and we found also the lowest postural sway is in the MS when serum concentration of estradiol are relatively low.

In conclusion, postural instability increased during OV compared to MS and LP in healthy female. According of more postural sway in OV sport trainer or health trainer should be aware of these physiological conditions. Further studies in this area, including a larger number of subjects, especially with athletes, are necessary to confirm the effect of the menstrual cycle on postural balance revealed by our results.

\section{CONFLICT OF INTEREST}

No potential conflict of interest relevant to this article was reported.

\section{REFERENCES}

Adkin AL, Bloem BR, Allum JH. Trunk sway measurements during stance and gait tasks in Parkinson's disease. Gait Posture 2005;22:240249.

Bartolić A, Pirtosek Z, Rozman J, Ribaric S. Postural stability of Parkinson's disease patients is improved by decreasing rigidity. Eur J Neurol 2005;12:156-159.

Bonuccelli U, Melis GB, Paoletti AM, Fioretti P, Murri L, Muratorio A. Unbalanced progesterone and estradiol secretion in catamenial epilepsy. Epilepsy Res 1989;3:100-106.

Darlington CL, Ross A, King J, Smith PF. Menstrual cycle effects on postural stability but not optokinetic function. Neurosci Lett 2001;307:147150.

Fridén C, Hirschberg AL, Saartok T. Muscle strength and endurance do not significantly vary across 3 phases of the menstrual cycle in moderately active premenopausal women. Clin J Sport Med 2003a;13:238241.

Fridén C, Hirschberg AL, Saartok T, Bäckström T, Leanderson J, Renström $P$. The influence of premenstrual symptoms on postural balance and kinesthesia during the menstrual cycle. Gynecol Endocrinol 2003b;17:433-439.

Fridén C, Ramsey DK, Backstrom T, Benoit DL, Saartok T, Lindén Hirschberg A. Altered postural control during the luteal phase in women with premenstrual symptoms. Neuroendocrinology 2005;81:150-157.

Girdler SS, Pedersen CA, Stern RA, Light KC. Menstrual cycle and premenstrual syndrome: modifiers of cardiovascular reactivity in women. Health Psychol 1993;12:180-192.

Grunfeld E, Gresty MA. Relationship between motion sickness, migraine and menstruation in crew members of a "round the world" yacht race. Brain Res Bull 1998;47:433-436.

Hampson E. Estrogen-related variations in human spatial and articulatory-motor skills. Psychoneuroendocrinology 1990;15:97-111.

Hertel J, Williams NI, Olmsted-Kramer LC, Leidy HJ, Putukian M. Neuromuscular performance and knee laxity do not change across the menstrual cycle in female athletes. Knee Surg Sports Traumatol Arthrosc 2006;14:817-822.

Holbein MA, Redfern MS. Functional stability limits while holding loads 
in various positions. Int J Ind Ergon 1997;19:387-395.

Horak FB. Postural orientation and equilibrium: what do we need to know about neural control of balance to prevent falls? Age Ageing 2006;35 Suppl 2:ii7-ii11.

Huijing PA, Jaspers RT. Adaptation of muscle size and myofascial force transmission: a review and some new experimental results. Scand J Med Sci Sports 2005;15:349-380.

Ibrahim MS, Mattar AG, Elhafez SM. Efficacy of virtual reality-based balance training versus the Biodex balance system training on the body balance of adults. J Phys Ther Sci 2016;28:20-26.

Kelly G. Body temperature variability (Part 1): a review of the history of body temperature and its variability due to site selection, biological rhythms, fitness, and aging. Altern Med Rev 2006;11:278-293.

Kimura D. Sex differences in the brain. Sci Am 1992;267:118-125.

Laessle RG, Tuschl RJ, Schweiger U, Pirke KM. Mood changes and physical complaints during the normal menstrual cycle in healthy young women. Psychoneuroendocrinology 1990;15:131-138.

Lee H, Petrofsky JS, Daher N, Berk L, Laymon M. Differences in anterior cruciate ligament elasticity and force for knee flexion in women: oral contraceptive users versus non-oral contraceptive users. Eur J Appl Physiol 2014;114:285-294.

Lemoine S, Granier P, Tiffoche C, Rannou-Bekono F, Thieulant ML, Delamarche P. Estrogen receptor alpha mRNA in human skeletal muscles. Med Sci Sports Exerc 2003;35:439-443.

Luine VN. Estradiol increases choline acetyltransferase activity in specific basal forebrain nuclei and projection areas of female rats. Exp Neurol 1985;89:484-490

Mancini M, Rocchi L, Horak FB, Chiari L. Effects of Parkinson's disease and levodopa on functional limits of stability. Clin Biomech (Bristol, Avon) 2008;23:450-458.

McEwen B. Ovarian steroids have diverse effects on brain structure and function. In: Berg G, Hammar M, editors. The modern management of the menopause: a perspective for the 21st century : the proceedings of the VII International Congress on the Menopause, Stockholm, Sweden 1993. New York: Parthenon; 1994; 269-278.

Owen JA Jr. Physiology of the menstrual cycle. Am J Clin Nutr 1975;28: 333-338.

Petrofsky J, Lee H. Greater reduction of balance as a result of increased plantar fascia elasticity at ovulation during the menstrual cycle. Tohoku J Exp Med 2015;237:219-226.

Posthuma BW, Bass MJ, Bull SB, Nisker JA. Detecting changes in func- tional ability in women with premenstrual syndrome. Am J Obstet Gynecol 1987;156:275-278.

Rozzi SL, Lephart SM, Fu FH. Effects of muscular fatigue on knee joint laxity and neuromuscular characteristics of male and female athletes. J Athl Train 1999;34:106-114.

Sarwar R, Niclos BB, Rutherford OM. Changes in muscle strength, relaxation rate and fatiguability during the human menstrual cycle. J Physiol 1996;493(Pt 1):267-272.

Sato N, Miyake S, Akatsu J, Kumashiro M. Power spectral analysis of heart rate variability in healthy young women during the normal menstrual cycle. Psychosom Med 1995;57:331-335.

Schieppati M, Hugon M, Grasso M, Nardone A, Galante M. The limits of equilibrium in young and elderly normal subjects and in parkinsonians. Electroencephalogr Clin Neurophysiol 1994;93:286-298.

Sherwin BB. Estrogenic effects on memory in women. Ann N Y Acad Sci 1994;743:213-230.

Shultz SJ, Pye ML, Montgomery MM, Schmitz RJ. Associations between lower extremity muscle mass and multiplanar knee laxity and stiffness: a potential explanation for sex differences in frontal and transverse plane knee laxity. Am J Sports Med 2012;40:2836-2844.

Stoney CM, Owens JF, Matthews KA, Davis MC, Caggiula A. Influences of the normal menstrual cycle on physiologic functioning during behavioral stress. Psychophysiology 1990;27:125-135.

Sung E, Han A, Hinrichs T, Platen P. Endurance training \& menstrual cycle: Effects of follicular \& luteal phase-based training in subjects with oral contraception: 1566. Med Sci Sports Exerc 2010;42:320.

Sung E, Han A, Hinrichs T, Vorgerd M, Manchado C, Platen P. Effects of follicular versus luteal phase-based strength training in young women. Springerplus 2014;3:668.

Woolley CS. Effects of estrogen in the CNS. Curr Opin Neurobiol 1999;9:3 49-354.

Woolley CS, McEwen BS. Estradiol mediates fluctuation in hippocampal synapse density during the estrous cycle in the adult rat. J Neurosci 1992;12:2549-2554.

Yu WD, Liu SH, Hatch JD, Panossian V, Finerman GA. Effect of estrogen on cellular metabolism of the human anterior cruciate ligament. Clin Orthop Relat Res 1999;(366):229-238.

Zazulak BT, Paterno M, Myer GD, Romani WA, Hewett TE. The effects of the menstrual cycle on anterior knee laxity: a systematic review. Sports Med 2006;36:847-862. 